\title{
A Comparative Study of the Two Dimensions of Parenting Style and their Effects on the Self-Concept of Pre-Adolescents
}

\author{
Dr. Giselle D’souza*, Dr. Jennie Mendes**
}

\section{ABSTRACT:}

Self-concept of adolescents has been one of the personality constructs that has attracted the attention of psychologists and educationists the world over. Since it is crystallized during adolescence, impacting the self-worth of youth, it becomes imperative to look into determinants of this variable in an attempt to protect their mental health. Among a myriad different factors which are thought to be responsible for influencing self-concept of teens, parenting styles has played a pivotal role. The present research endeavored to study the effect of parenting styles on the self-concept of pre-adolescents with respect to two dimensions of the namely: responsiveness and demandingness of both parents. The results indicated a significant difference in the selfconcept of pre-adolescents depending on the parenting dimension of mothers/fathers. The study attempted to explore the potential benefits of either parenting dimension in boosting the selfconcept of gen next.

Keywords: Self-concept, parenting style, responsiveness, demandingness.

\section{INTRODUCTION}

Parenting styles have been investigated for several decades and are considered predictors of behavior among young individuals (Weber, Selig, Bernardi, and Salvador, 2006). This responsibility on the part of parents is a constant that transcends the diversity of social standards, making it possible to identify behavioral characteristics or styles adopted by parents in the daily socialization of their children (MusituandGarcía,2001).Parenting styles can be seen as a set of behaviors of fathers and mothers in the children's socialization process (Kobarg, Vieira, and Vieira,2010). The variability of parents' behavior in relation to the socialization of their children has been satisfactorily explained by two basic dimensions, which, despite other terms used by researchers, can be called parental control (demandingness) and affection (responsiveness) (Musitu, Estévez, Martínez, and Jiménez, 2008). Control implies making demands, supervision, and requirements imposed by maternal and paternal figures, while affection in volves sensitivity, acknowledgement and commitment of parents to their children (Baumrind , 2005; Weaver and Prelow, 2005).

\footnotetext{
*Associate Professor, St. Teresa's Institute of Education, Mumbai.

**Associate Professor, Ophia College for Women, Mumbai.
}

(C) 2014 G D'souza, J Mendes; licensee IJIP. This is an Open Access Research distributed under the terms of the Creative Commons Attribution License (http://creativecommons.org/licenses/by/2.0), which permits unrestricted use, distribution, and reproduction in any Medium, provided the original work is properly cited. 


\section{A Comparative Study of the Two Dimensions of Parenting Style and their Effects on the Self-Concept of Pre-Adolescents}

The term self-concept refers to the ordered set of attitudes and perceptions that an individual holds about him/ her (Wolffe 2000; Woolfolk 2001 and Tuttel and Tuttel 2004). Self-concept is defined as the value that an individual places on his or her own characteristics, qualities, abilities, and actions (Woolfolk2001).The positive or negative life experiences one has, creates attitudes toward the self which can be favorable and develop positive feelings of self-worth, or can be unfavorable and develop negative feelings of self-worth. The emphasis of unconditional love, in parenting how-to books, represents the importance of a child developing a stable sense of being cared for and respected.

Parenting style can also play a crucial role in self-concept development. Studies thus far have reported a correlation of warm, supportive parenting styles and children having high selfconcept, thus suggesting a causal effect of the responsive parenting dimension in self-concept development (Coopersmith, 1967; Isberg et al, 1989; Lamborn et al, 1991). The root of selfconcept lies in family experiences. A favorable home environment constitutes of good parentchild relationship. Parenting style thus has a potential bearing on the self-concept of preadolescents.

\section{Operational Definition of the Terms}

The following terms are defined to clarify their use in the context of this study:

PARENTING STYLE: 'Parenting Style' in the present study refers to the methods that parents use to interact with their children and run their families and includes two important components of parenting namely,

$\checkmark$ Responsiveness which indicates how parents respond to their children's needs and expectations, including their warmth and supportiveness to them

$\checkmark$ Demandingness which indicates how parents go about imposing their needs and expectations on their children through behavioral controls, discipline, rule setting and enforcement.

SELF-CONCEPT: 'Self-Concept 'in the present study has been defined as the relatively stable idea possessed by a student based on a combination of judgments by self and "significant others" (parents, teachers and peers), concerning his/her behaviour, strengths and weaknesses in the academic and non-academic domains.

\section{AIM OF THE STUDY}

To Study the Effect of Parenting Style on the Self-Concept of Pre-Adolescents. 


\section{OBJECTIVES OF THE STUDY}

1. To study the difference between the self-concept of pre-adolescents whose mothers have a predominantly responsive $\mathrm{v} / \mathrm{s}$ demanding parenting style?

2. To study the difference between the self-concept of pre-adolescents whose fathers have a predominantly responsive $\mathrm{v} / \mathrm{s}$ demanding parenting style?

\section{HYPOTHESES OF THE STUDY}

In order to prove the research hypotheses by subjecting the data to statistical analysis, null hypotheses were formulated for the study which are as follows:

1. There is no significant difference between the self-concept of pre-adolescents whose mothers have a predominantly responsive $\mathrm{v} / \mathrm{s}$ demanding parenting style.

2. There is no significant difference between the self-concept of pre-adolescents whose fathers have a predominantly responsive $\mathrm{v} / \mathrm{s}$ demanding parenting style.

\section{METHODOLOGY}

The present investigation aimed to study the effect of parenting style on the self-concept of preadolescent students of standard VII. It was a descriptive research as it involved collecting data using self-reporting tools to test hypotheses or answer questions concerning the selected variables. Moreover, the present study was of the comparative type because it sought to study the difference in the self- concept of pre-adolescents based on the predominant parenting dimension of their mothers and fathers.

\section{Sampling:}

In the present study, a two stage sampling procedure was used. At the first stage stratified random sampling was used wherein the strata were the divisions of standard VII of one convent school for girls located in Mumbai. Of the 4 divisions, 2 divisions were chosen. At the second stage incidental sampling procedures were employed to select students of standard VII from these 2 divisions who were conveniently available for the data collection. The school selected was a secondary private aided school with English as the medium of instruction and affiliated to the S.S.C. Board. It was a girls' school. The sample comprised of 101 female students studying in standard VII. The reason behind selecting standard VII for the study was that these students are at the pre-adolescent stage of development and their self-concept is in a period of crystallization.

\section{Tools}

\section{$\checkmark$ Parental Perceptions Questionnaire-PPQ (Pasqualiand Araújo, 1986)}

This tool has $\mathbf{4 0}$ items. 
10 items pertain to the responsiveness of the mother and had an internal consistency (Cronbach's alpha) of 0.84 .

10 items pertain to the demandingness of the mother with an internal consistency (Cronbach's alpha) of 0.73.

10 items pertain to the responsiveness of the father with an internal consistency (Cronbach's alpha) of 0.86 .

$>10$ items pertained to the demandingness of the father with an internal consistency (Cronbach's alpha) of 0.85.The participants were asked to indicate for each item, on a fivepoint scale, the extent to which the described behavior or attitude was applicable to either of the parents. The scale ranged from0 (not applicable) to 4(totally applicable).

\section{$\checkmark$ Self-Description Questionnaire I-SDQI ( Marsh, 1992)}

This tool is designed to measure multiple dimensions of self-concept for pre-adolescents. In particular, the scale taps self-perceptions relative to four non-academic areas (Physical Ability, Physical Appearance, Peer Relations, and Parent Relations) and three academic areas (Reading, Mathematics, and school in general), as well as a global perception of self. The SDQI instrument is solidly grounded in Shave son/Marsh's multidimensional/hierarchical self- concept model (1985). The tool has 8 sub-scales and $\mathbf{7 6}$ items in all. 9 items pertain to Physical Ability, 9 items pertain to Physical Appearance, 9 items pertain to Peer Relations and 9 items to Parent Relations. In the 3 academic areas each sub-scale contains 10 items, while 10 items pertain to the global perception of self. It is a five point Likert scale, wherein students have to respond to each item by selecting either one of the choices ranging from false, mostly false, sometimes falsesometimes true, mostly true and true. There are in all 12 negatively worded items in order to disrupt positive response biases. Internal consistency is .80 to .92 and the test-retest reliability is .50 to .70 .

\section{Data Collection}

After obtaining the readymade tool, the researcher approached the school authorities and requested them to grant permission for the collection of data from their institutions. The investigator assured the principal of the anonymity and confidentiality of all the data collected. Before distributing the questionnaires and administering the tools to the students, the researcher established cordial relations with them to win their confidence and establish rapport. The purpose of the study was also briefly conveyed to them. The detailed instructions for giving responses to the items of the tests were then explained and doubts clarified. The same instructions were also printed on the first page of each tool being used. The students were given on an average one hour to complete the survey form and completed forms were then collected by the researcher in person. 


\section{Analysis of the Data}

The study involved the following inferential statistical techniques for testing of the null hypotheses:

$\checkmark$ Student's t-test to compare the Mean Scores of self-concept of pre-adolescents based on the pre-dominant parenting dimension of the mother/father.

\section{Testing Hypothesis 1:}

The null hypothesis states that there is no significant difference between the self-concept of preadolescents whose mothers have a predominantly responsive v/s demanding parenting style.

Table 5.1 shows the relevant statistics of the SCS of pre-adolescents whose mothers have a predominantly responsive $\mathrm{v} / \mathrm{s}$ demanding parenting style.

\section{TABLE 5.1}

Relevant statistics of the SCS of pre-adolescents based on the predominant parenting dimension of the mother

\begin{tabular}{|c|c|c|c|c|c|c|}
\hline $\begin{array}{c}\text { PREDOMINANT PARENTING } \\
\text { DIMENSION OF THE } \\
\text { MOTHER }\end{array}$ & $\mathbf{N}$ & Mean & SD & t-ratio & $\begin{array}{c}\text { Level } \\
\text { of } \\
\text { significanc } \\
\text { e }\end{array}$ & $\begin{array}{l}100 \omega^{2} \\
\text { estimate }\end{array}$ \\
\hline RESPONSIVENESS & 87 & 284.09 & 36.763 & & & \\
\hline DEMANDINGNESS & 13 & 251.31 & 41.17 & 2.71 & 0.01 & 5.97 \\
\hline
\end{tabular}

The tabulated values for 't' are as follows (Garett, 1985):

For $\mathrm{df}=11$ and 85, $\mathrm{t}$ at 0.05 level $=2.20$ and 1.99 respectively, Similarly, for $\mathrm{df}=11$ and $85, \quad \mathrm{t}$ at 0.01 level $=3.11$ and 2.64 respectively.

Interpretation of ' $t$ ': The obtained t-ratio for the SCS of pre-adolescents based on predominant parenting dimension of the mother was 2.71 which is greater than 2.64 . Thus, ' $t$ ' is significant at 0.01 level. The null hypothesis is therefore rejected.

\section{CONCLUSION:}




\section{A Comparative Study of the Two Dimensions of Parenting Style and their Effects on the Self-Concept of Pre-Adolescents}

There is a significant difference in the SCS of pre-adolescents based on the predominant parenting dimension of the mother. The level of significance is 0.01 and the mean scores for girls having predominantly responsive mothers are higher than that of those having predominantly demanding mothers.

\section{DISCUSSION:}

An analysis of the results pertaining to the null hypothesis, indicate that there is a significant difference in the self-concept scores of pre-adolescents based on the predominant parenting dimension of the mother. In the present study, pre-adolescents having responsive mothers far outnumbered those having demanding mothers (i.e. $87 \mathrm{v} / \mathrm{s} 13$ ) which is itself suggestive of the fact that women are generally warm and supportive by nature. This observation is in keeping with the findings of studies which have shown that mothers tend to find themselves generally in a more nurturing role. They seem to have an innate ability to be discerning with their children. For example, they are often more tuned into a baby's specific needs than a father is. There is simply an emotional connection between mother and child that a father simply doesn't get. In addition, mothers tend to verbalize a lot more with their children. Part of that tendency is that women generally are more verbal than men. This tends to manifest itself in a parenting style where mothers offer more words of affirmation, express their expectations more clearly and "talk out" issues involving discipline. Mothers generally put their children's needs ahead of their

own. They seem to come "pre-wired" to self-sacrifice; perhaps that starts with pregnancy where a mother's full time physical care role is so dramatic. Research has also revealed that women are better at taking care of children than men are (Craig, 2006). Men and women are often believed to have certain traits that make men more successful in the work place, and women are better at taking care of children. There are several other reasons too why mothers or females are in reality better parents based on their natural intuition and compassionate tendencies. First of all, for a wide variety of socio-cultural reasons, women tend to have more intuitive intelligence than men. It is this intuition that enables the mother to know when her child needs her. In addition, women often know how to read non-verbal signals in human behavior, which can alert them to issues and problems in the child's life. All of these "perceptive skills" play a major role in making the mother a close, responsible and responsive parent. Men lack this kind of skill. Secondly, most mothers share a matchless bond with their children. Perhaps this bond arises during the nine months of pregnancy or maybe it is reinforced through the act of breastfeeding. Studies do show that breastfeeding is the perfect time for mother and child to build up a special relationship. Whatever the cause, there appears to be a lifelong silver chord or psychic connection between mother and child. As a result, the mother is able to analyze the child's actions. Although fathers may form deep loving bonds with their children, they may not be able to match the depth of closeness shared by mother and child. 
Pohl, Bender, and Lachman (2005) found that women tend to show more empathy than men, and men tend to be more assertive than women. People may assume that, that finding applies to all men and women and that there cannot be assertive women and empathetic men. Therefore, society often tends to assume that all women should take care of children and all men should focus on work and leave the childrearing to the mother. It is also assumed that mothers should have a closer relationship with their children than the fathers because mothers are supposed to be more focused on their children. The present study too revealed that higher number of adolescents had responsive as compared to demanding mothers and this responsiveness had in turn made a significant contribution to their self-concept. This is in keeping with the nurturing characteristics of women cited above. Figure 5.1 shows the difference in the SCS of pre-adolescents based on the predominant parenting dimension of the mother.

\section{Testing Hypothesis 2:}

The null hypothesis states that there is no significant difference between the self-concept of preadolescents whose fathers have a predominantly responsive $\mathrm{v} / \mathrm{s}$ demanding parenting style. Table 5.2 shows the relevant statistics of the SCS of pre-adolescents whose fathers have a predominantly responsive $\mathrm{v} / \mathrm{s}$ demanding parenting style.

\section{TABLE 5.2}

Relevant statistics of the SCS of pre-adolescents based on the predominant parenting dimension of the father

\begin{tabular}{|c|c|c|c|c|c|c|}
\hline $\begin{array}{c}\text { PREDOMINANT } \\
\text { PARENTING } \\
\text { DIMENSION OF THE } \\
\text { FATHER }\end{array}$ & $\mathbf{N}$ & Mean & SD & t-ratio & $\begin{array}{c}\text { Level of } \\
\text { significance }\end{array}$ & $\begin{array}{l}\mathbf{1 0 0} \boldsymbol{\omega}^{2} \\
\text { estimate }\end{array}$ \\
\cline { 1 - 5 } RESPONSIVENESS & 72 & 83.82 & 35.47 & 1.52 & $\begin{array}{c}\text { Not } \\
\text { Significant }\end{array}$ & 1.29 \\
\hline DEMANDINGNESS & 28 & 69.29 & 45.33 & & \\
\hline
\end{tabular}

The tabulated values for ' $t$ ' are as follows (Garett, 1985):

$$
\begin{aligned}
\text { For } \mathrm{df} & =26 \text { and } 70, \quad \mathrm{t} \text { at } 0.05 \text { level }=2.06 \text { and } 2 \text { respectively } \\
\text { Similarly, for } \mathrm{df} & =26 \text { and } 70, \quad \mathrm{t} \text { at } 0.01 \text { level }=2.78 \text { and } 2.65 \text { respectively. }
\end{aligned}
$$




\section{A Comparative Study of the Two Dimensions of Parenting Style and their Effects on the Self-Concept of Pre-Adolescents}

Interpretation of ' $t$ ': The obtained t-ratio for the SCS of pre-adolescents based on the predominant parenting dimension of the father was 1.52 which is less than 2 . Thus, ' $t$ ' is not significant. The null hypothesis is therefore accepted.

\section{CONCLUSION:}

There is no significant difference in the SCS of pre-adolescents based on the predominant parenting dimension of the father. However, the mean scores for girls having predominantly responsive fathers are slightly higher than that of those having predominantly demanding fathers.

\section{DISCUSSION:}

An analysis of the results pertaining to the null hypothesis, indicate that there is no significant difference in the self-concept scores of pre-adolescents based on the predominant parenting dimension of the father. Prior research studies have shown that fathers are generally more focused on having high expectations of their children and encouraging them to deliver on those consistently. They tend to focus less on making a child feel good or secure and more on challenging them and helping them prepare to cope with the real world. The emotional connection that a mother has is not often replicated in fathers.

Fathers, while they do not verbalize as much as mothers do, tend to be more direct with fewer words. They may seem to be "too tough" to the moms, but their toughness is rooted in helping kids be prepared for real life. From a disciplinary standpoint, they tend to impose consequences more quickly and then talk later. They also tend to be less self-sacrificing, at least in an obvious way. Their sacrifices tend to be more focused on the family as a whole and less on individual children. These qualities of fathers often lead pre-adolescents to believe that they are less responsive than mothers, resulting in them portraying their fathers to be demanding in their parenting style. This corroborates the fact that 72 pre-adolescents in the present study too, perceived their fathers to be demanding as compared to 28 of their counterparts who perceived their fathers to be responsive. However, the higher mean self-concept scores of the preadolescents with responsive fathers supports the possibility that fathers do have a critical role to play in the lives of their children but since they spend less time with their children on an average as compared to mothers (particularly in India) due to them being the 'bread-winners' of the family, it probably explains why the self-concept of adolescents is not significantly affected by the predominant parenting dimension of the father in the Indian scenario. Previous research in the West too has consistently found that mothers still spend two to three times as much time with children as fathers (Baxter, 2002; Yeung, Sandberg, Davis Kean, \& Hofferth, 2001). Some studies in the West, (Rebecca, 2006) have contrastingly shown that the perceived paternal parenting style is more influential than maternal parenting style in influencing adolescent outcomes. This could be attributed to the fact that unlike India, in western countries 
both parents are fairly equally involved in the up-bringing of the children as they may be professionally employed in part/full time jobs.

Figure 5.2 shows the difference in the SCS of pre-adolescents based on the predominant parenting dimension of the father.

\section{CONCLUSION}

The study revealed that parents may differ in their parenting styles, leading to a variation in the self-concept of pre-adolescents. Individually, each of these differences in parents seems to bring out different qualities in children, but probably the most important benefit of these differences is visible when viewed in total. All-in-all, it is the combination of involved mothers and fathers and their unique styles that make the biggest difference for children and their future health and happiness.

\section{DIFFERENCE IN THE SCS OF PRE-ADOLESCENTS BASED ON} THE PREDOMINANT PARENTING DIMENSION OF THE MOTHER

\section{DIFFERENCE BETWEEN THE SCS OF PRE-ADOLESCENTS BASED ON THE PREDOMINANT PARENTING DIMENSION OF THE MOTHER}

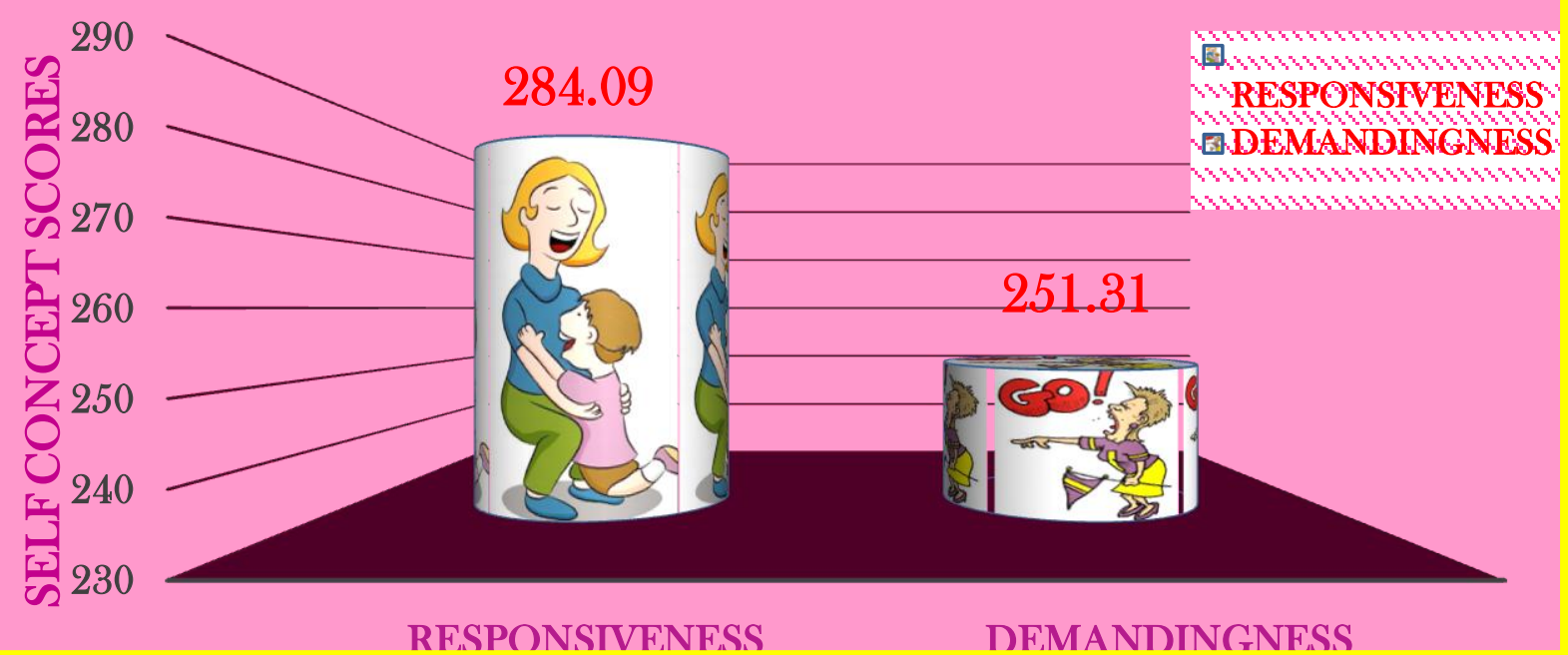

FIGURE 5.1 


\section{DIFFERENCE IN THE SCS OF PRE-ADOLESCENTS BASED ON}

THE PREDOMINANT PARENTING DIMENSION OF THE FATHER

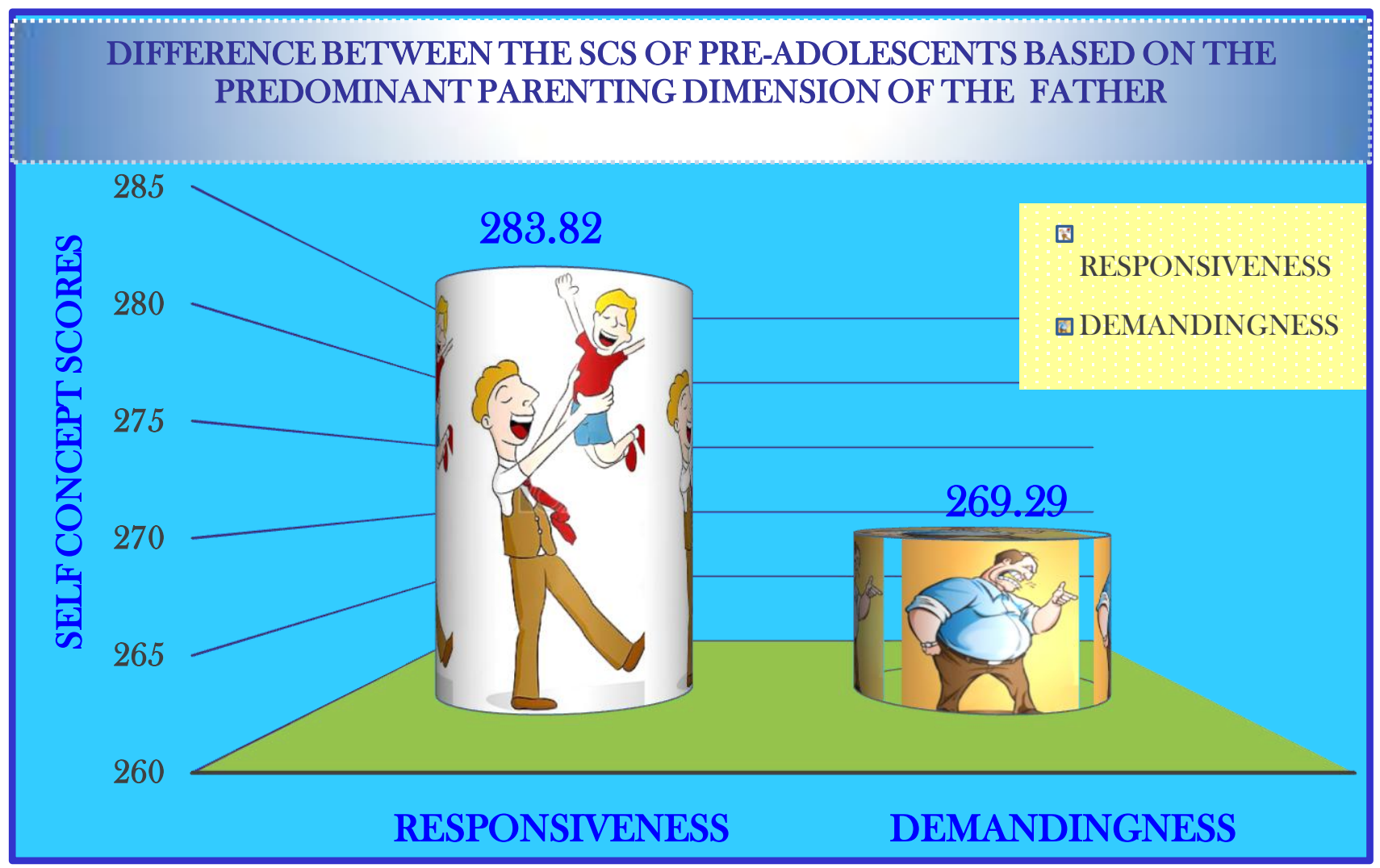

FIGURE 5.2

\section{REFERENCES}

1. Baumrind, D. (2005). Patterns of parental authority and adolescent autonomy. New Directions for Child and AdolescentDevelopment,108,61-69.doi:10.1002/cd.128

2. Baxter,J.(2002). Patterns of change and stability in the gender division of house hold labour in Australia, 1986- 1997. Journal of Sociology, 38(4), 399-424.

3. Cooper smith, S. (1967). The Antecedents of Self-concept. New York: W.H. Freeman.

4. Craig,L.(2006). Does Father Care Mean Fathers Share?A Comparison of How M others

and Fathers in Intact Families Spend Time with Children. Gender andSociety,20 (2), 259- 281.

5. Garett, H.E. (1985). Statistics in Psychology and Education. Bombay:Vakils, Feffers and Simons Ltd, p. 455. 
6. Isberg, R.S., Hauser, S.T., Jacobson, A.M., Powers, S.I., Noam, G., Weiss-Perry, B., and Fullansbee, D. (1989). Parental Contexts of Adolesecent Self-concept: A Developmental Perspective. Journal of Youth and Adolescence, 18, 1-23.

7. Kobarg, A. P. R. ,Vieira, V., and Vieira, M. L. (2010). Validação daescaladelembrançassobrepráticasparentais (EMBU). Avaliação Psicológica, 9(1), 77-85.

8. Lamborn,S.D., Mounts, N.S., Steinberg, L and Dornbusch, S.M. (1991). Patterns of Competence and Adjustment among Adolescents from Authoritative, Authoritarian, Indulgent, and Neglectful Families. Child Development, 62(5), 1049-1065.

9. Marsh, H. W. (1992). Self Description Questionnaire (SDQ) I: A theoretical and empirical basis for the measurement of multiple dimensions of preadolescentself-concept. An interim test manual and research monograph. Macarthur, New South Wales, Australia: University of Western Sydney, Faculty of Education.

10. Musitu, G. \&García, F., 2001, ESPA29: EscalaDe Estilos De Socialización Parental En La Adolescencia (2nd Ed.). Madrid, Spain, Tea.

11. Musitu,G.,Estévez,E.,Martínez,B.,and Jiménez,T.(2008). La adolescencia y suscontextos: Familia, escuela e iguales. Madrid: Pearson Educación.

12. Pasquali,L., and Araújo,J.M.A.(1986).Questionáriode PercepçãodosPaisQPP.Psicologia:TeoriaePesquisa,

13. Pohl, R. F., Bender, M., and Lachmann, G. (2005). Autobiographical Memory and Social Skills of Men and Women. Applied Cognitive Psychology, 19,745-759.

14. Rebecca, A.P. (2006). Effects of Parenting Style on Personal and Social Variables for Asian Adolescents. American Journal of Orthopsychiatry, 76(4), 503-511.

15. Tuttel D and Tuttel N.(2004). Self-esteem and Adjusting withBlindness.3rdEdition,Springfield,IL.Charles.

16. Weaver, S. R, and Prelow, H. M. (2005). A Mediated- Moderation Model of Maternal Parenting Style, Association with Deviant Peers, and Problem Behaviors in Urban African American and European American Adolescents. Journal of Child and Family Studies, 14(3), 343-356. doi: 10.1007/s10826-005-6847-1.

17. Weber, L. N .D. ,Selig, G. A. ,Bernardi, M. G., and Salvador, A. P. V. (2006). Continued edosestilosparentai sat raves das gerações-transmissão inter geracional de estilosparentais.Paidéia, 16(35),407-414.doi:10.1590/ S0103-863X2006000300011.

18. WolffeK. (2000). Growth and development in middle Childhood and adolescence. In: A J Koenig, MC Holbrook (Eds). Foundations of Education,1, 135-156.

19. Woolfolk A. (2001). Educational Psychology. $8^{\text {th }}$ Edition, Need ham Heights, MA: Allyn and Bacon.

20. Yeung, W., Sandberg, J., DavisKean, P., andHofferth, S. (2001).Children's time with fathers in intact families. Journal of Marriage and Family, 63(1), 136-154. 